\title{
A Homeodomain Protein Selectively Expressed in Noradrenergic Tissue Regulates Transcription of Neurotransmitter Biosynthetic Genes
}

\author{
Eustacia Zellmer, ${ }^{1}$ Zheng Zhang, ${ }^{2}$ Dominique Greco, ${ }^{1}$ Jennifer Rhodes, ${ }^{1}$ Suzanne Cassel, ${ }^{1}$ and Elaine J. \\ Lewis $^{1,2}$
}

Departments of 'Molecular and Medical Genetics and ${ }^{2}$ Biochemistry and Molecular Biology, Oregon Health

Sciences University, Portland, Oregon 97201

In order to characterize the specificity of expression of the neurotransmitter biosynthetic gene dopamine $\beta$-hydroxylase (DBH), the identification of proteins that interact with the DB1 enhancer was initiated. A homeobox-containing cDNA was isolated from a PC12 expression cDNA library screened with the DB1 enhancer. The homeodomain is a member of the paired-like class, and is encoded by several nonidentical cDNAs. The cDNAs contain the same sequence in the homeodomain and $3^{\prime}$ coding and noncoding sequences, but diverge in sequence $5^{\prime}$ to the homeodomain. This family of homeobox-containing cDNAs is named Arix. Arix mRNA transcripts are found only in noradrenergic, DBH-positive tissues, and in cell lines derived from those tissue. The DB1 enhancer contains two binding sites for the Arix homeodomain, and both sites contribute to basal activity of the DBH promoter. When introduced into tissue culture, Arix regulates the transcriptional activity from the DBH promoter, and also from the promoter of the tyrosine hydroxylase gene, encoding the initial enzyme of the catecholamine biosynthetic pathway. The pattern of expression of the Arix transcripts, the presence of the homeodomain, and the transcriptional regulatory properties suggest that this family of proteins may be involved in the specificity of expression of the catecholamine biosynthetic genes.

[Key words: Phox2, homeodomain protein, catecholaminergic phenotype, tyrosine hydroxylase, dopamine B-hydroxylase, PC12 cell, transcription factor, sympathoadrenal]

The development and maintenance of the appropriate neurotransmitter phenotype of a neuroendocrine cell is a critical event for proper cellular function. The genes encoding neurotransmitter precursors and biosynthetic enzymes are under the control of complex genetic regulatory signals, encompassing both positive and negative influences on transcription. Several transcription factors have been identified which interact with regulatory ele ments on neurotransmitter biosynthetic genes to modulate tran-

Received Feb. 8, 1995; revised Aug. 8, 1995; accepted Aug. 14, 1995.

This work is supported by NIH Grant GM38696 to E.L. We thank Rich Maurer for critical evaluation of the manuscript.

Correspondence should be addressed to Elaine Lewis, Department of Biochemistry and Molecular Biology, L224, Oregon Health Sciences University, Portland, OR 97201.

Copyright $(\mathcal{C} 1995$ Society for Neuroscience $0270-6474 / 95 / 158109-12 \$ 05.00 / 0$ scription in response to environmental stimuli, including members of the CREB and fos/jun families (Gizang-Ginsberg and Ziff, 1990, 1994; Icard-Liepkalns et al., 1992; Stachowiak et al., 1992; Konradi et al., 1993). In contrast, few transcription factors have been identified that are likely to play a role in the determination of the cellular specificity of the neurotransmitter biosynthetic gene expression.

The search for transcriptional regulatory factors which determine cell fate in other systems has led to the identification of several different classes of DNA-binding proteins, which are usually classified by the motif of the DNA-binding domain. Those classes of proteins that have been demonstrated to directly influence a cell phenotype include (1) the helix-loop-helix family, which include the myogenic regulatory proteins myoD, myf5, and myogenin (Weintraub et al., 1991), and (2) the homeobox family, members of which were initially found to determine segment identity in Drosophila, and which have subsequently been found in nearly all animals, from flatworms to humans (see Gehring et al., 1993; Krumlauf, 1994). A subclass of homeobox proteins, the POU family of transcriptional activators (Herr et al., 1988), also exert influence on the development of cellular identity. These helix-loop-helix, homeobox and POU genes have often been referred to as "master regulatory switches" or "master control genes" because they are able to program the development of specific structures in both vertebrates and invertebrates.

Several studies have sought the identification of transcription factors that may program a specific neuronal phenotype. In the cranial neural crest, the temporal and spatial expression of defined hox genes lead to the development of cranial sensory ganglia (Krumlauf et al., 1994). Two additional transcription factors have been identified which exhibit selective expression in the developing central and peripheral nervous systems, MASH1 (Johnson et al., 1990; Lo et al., 1991) and Phox2 (Valarche et al., 1993). MASH , a basic helix-loop-helix protein, is expressed in developing forebrain and in precursors of sympathetic and enteric neurons, and is essential for the development of autonomic neurons (Guillemot et al., 1993). Phox2, a homeodomain protein, was originally isolated via interaction with an NCAM enhancer, but exhibits an expression pattern in the developing nervous system that is correlated with noradrenergic cell types. Phox 2 is expressed in the sympathetic primordia at e10, prior to onset of markers of the noradrenergic phenotype, and is also expressed in the developing hindbrain, in the immature locus ceruleus (Valarche et al., 1993). 
The catecholamine neurotransmitters dopamine and norepinephrine are localized to specific neuroendocrine cell types, including the sympathetic ganglia, the adrenal medulla and the brain nucleus locus ceruleus. The production of dopamine is catalyzed by the enzyme tyrosine hydroxylase $(\mathrm{TH})$, while the production of norepinephrine is dependent upon the activity of dopamine $\beta$-hydroxylase (DBH). The postnatal expression of both of these proteins, as well as their mRN $\Lambda$ transcripts, is restricted to those cells producing the transmitters. Several regulatory elements that contribute to the specificity of expression of these genes have been described (Cambi et al., 1989; Fung et al., 1992; Shaskus et al., 1992; Yoon and Chikaraishi, 1992; Ishiguro et al., 1993; Kim et al., 1993; Lamouroux et al., 1993; Wong et al., 1994). For the tyrosine hydroxylase gene, several promotcr proximal positive-acting elements have been identified which influence the expression of the TH promoter in tissue culture cells (Fung et al., 1992; Yoon and Chikaraishi, 1992; Kim et al., 1993; Wong et al., 1994). One element, composed of two motifs, a variant AP1 site and an E-box containing a region of dyad symmetry, interacts with transcription factors CDP2 and ITF2, which together stimulate transcription from the TH promoter (Yoon and Chikaraishi, 1994). The CRE element between -40 and -50 of the rat TH gene regulates both basal $\mathrm{TH}$ gene transcription and the stimulation of transcription observed with the second messenger cAMP (Kim et al., 1993). For the $\mathrm{DBH}$ gene, promoter proximal positive regulatory elements have been identified between -180 and -150 in the rat gene (Shaskus et al., 1992), -189 and -170 in the human gene (Ishiguro et al., 1993; Lamouroux et al., 1993) that contribute to expression from the $\mathrm{DBH}$ promoter. This region plays a role in both second messenger mediated and basal transcription from the $\mathrm{DBH}$ promoter in catecholaminergic cells. Other positiveacting regulatory elements in the DBH gene include an AP2 site at position - 129 (Greco et al., 1995) and a promoter distal site between -600 and -1100 of the human DBH gene (Hoyle et al., 1994), which is active in the specificity of expression in transgenic mice. In addition, negative regulatory elements, which repress DBH transcription in inappropriate cell types, have been identified in both promoter proximal and promoter distal regions (Ishiguro et al., 1993; Hoyle et al., 1994; Shaskus et al., 1995). These studies indicate that the genes encoding the catecholamine biosynthetic enzymes are under the control of complex genetic regulatory signals, encompassing both positive and negative influences on transcription.

In order to further understand the specificity of $\mathrm{DBH}$ gene transcription, we have sought to identify proteins that interact with the DB1 enhancer, which exhibits regulatory properties in a cell type selected pattern and also mediates a response to the protein kinase A and C systems (Shaskus et al., 1992). The study reported here describes the isolation and characterization of a family of homeobox-containing cDNAs, named Arix, that bind to the $\mathrm{DBH}$ enhancer and regulate transcription from both $\mathrm{DBH}$ and $\mathrm{TH}$ promoters. The pattern of expression of Arix transcripts, plus the presence of the homeodomain motif, suggest that Arix proteins may play a role in regulating the specificity of expression of the TH and DBH genes.

The GeneBank accession number for Arixl is U25967.

\section{Materials and Methods}

Cell culture. All cell lines were cultured in a humidified atmosphere containing $5 \% \mathrm{CO}_{2}$ at $37^{\circ} \mathrm{C}$. PC1 2 cells were cultured in DMEM plus $10 \%$ fetal calf serum (FCS) and 5\% horse serum. HepG 2 human he- patoma cells were cultured in MEM plus $10 \%$ FCS, $1 \times$ nonessential amino acids and $1 \mathrm{~mm}$ sodium pyruvate. All sera were purchased from HyClone Laboratories (Logan, UT).

Library screening and selection of Arix cDNAs. A cDNA expression library from $\mathrm{PC} 12$ cells constructed in $\lambda$ gt1l was screened using the procedure of Singh et al. (1989). Double-stranded DB1 oligonucleotide containing four base extended ends, 5 'GATCATGTCCATGCGTCATTAGTGTCAATTAGGG, was end-labeled with ${ }^{32} \mathrm{P}$ and ligated to form concatamers. The concatanated oligonucleotide was used to probe the $\lambda$ gtll library. One positive clone was selected from a screen of 100,000 , and was plaque purified and subcloned into pSP72 for DNA sequence analysis. This cDNA is named DB1BP.

The DB1BP cDNA was used to select additional cDNAs from PC12 and rat adrenal libraries. One additional cDNA was isolated with a $5^{\prime}$ extended end corresponding to that of DR1RP. This CDNA was selected from a different library than the original DB1BP. The composite DNA sequence for these two cDNAs is referred to as Arix2.

Five cDN $\Lambda$ s were isolated that have a different $5^{\prime}$ terminal sequence than the Arix 2 class, and contain uniform overlapping sequence similarity with each other. The longest cDNA in this class was $1.65 \mathrm{~kb}$, which was sequenced in entirety. The $5^{\prime}$ end of the $1.65 \mathrm{~kb}$ cDNA was extended and cloned using the $5^{\prime}$ RACE (Rapid Amplification of cDNA Ends) System (GIBCO/BRL). Oligonucleotides specific for Arix that were used for the 5' RACE extension are: (1) GAACTTGTAGGGAACTGCCGAGTA, representing the complement of sequences 428-405 (see Fig. $1 B$ ), used as the primer for cDNA synthesis; (2) GTGGAGTTCGGGACGGAGATTC, representing the complement of sequences 117-95, used in the initial PCR amplification; and (3) AAGACCTGAGACCCACTCTGAGT, representing the complement of sequence 79-57, used in the second PCR amplification. The composite DNA sequence of these five overlapping cDNAs, plus the 5' RACE PCR extension products, is referred to as Arix 1.

Transfection of DNA into cultured cells. Transfection of plasmid DNAs into cultured cells was performed using the calcium phosphate method (Graham and van der Eb, 1973), as described in Sambrook et al. (1989). In experiments where the expression of reporter gene activity was to be compared between different plasmid constructs, a luciferase standardization plasmid, under control of the RSV promoter and enhancer elements, (RSV-L; deWet et al., 1987) was included in the transfection mixture. Cell extracts were assayed for both CAT (Gorman et al., 1982) and luciferase (deWet et al., 1987) activities.

Electrophoretic mobility shift assay. The interaction of DNA binding proteins with the DB 1 regulatory clement was cvaluatcd using the electrophoretic mobility shift assay (EMSA). The DB1 oligonucleotide was end-labeled with ${ }^{32} \mathrm{P}$ using T4 polynucleotide kinase. Nuclear extracts from PC12 cells were prepared by the method of Dignam et al. (1983). Purified GST-Arix fusion protein or PC12 nuclear extracts were incubated at room temperature in a mixture containing $10 \mathrm{mM}$ HEPES $\mathrm{pH}$ 7.9, $7 \%$ glycerol, $35 \mathrm{~mm} \mathrm{KCl,} 1 \mathrm{~mm}$ EDTA, $1 \mathrm{~mm}$ DTT, $5 \mathrm{~mm} \mathrm{MgCl}_{2}$, and $1.5 \mu \mathrm{g}$ dIdC in a total volume of $20 \mu \mathrm{l}$. DNA-protein complexes were separated from probes by electrophoresis in a $6 \%$ polyacrylamide gel.

Analyses of RNA transcripts. Total RNA from tissue culture or rat tissue was extracted using either the guanidine acid phenol method (Chomczynski and Sacchi, 1987) or LiCl/urea as previously described (Shaskus et al., 1992). For Northern blot analyses, total RNA was fractionated by formaldehyde-agarose gel electrophoresis as described. RNA was transferred to Nytran and hybridized with DNA radiolabeled using random primers and ${ }^{32} \mathrm{P}-\mathrm{dCTP}$ (Ready to Go DNA Labeling Kit, Pharmacia).

For RNAse protection assay, antisense probes were generated between bases 1620 and 1264 for regions common to all Arix transcripts, and between bases 489 and 269 for the region specific to Arix 1. For the assay of TH RNA transcripts, an antisense probe was generated corresponding to bases 1520-1240 of the full length TH cDNA (Grima et al., 1985). RNA probes were synthesized using ${ }^{32} \mathrm{P}$ UTP and were purified by polyacrylamide gel electrophoresis. The RNAse protection assay was performed as previously described (Shaskus et al., 1992). Each sample contained $10 \mu \mathrm{g}$ of RNA, composed of $1-10 \mu \mathrm{g}$ of rat tissue RNA plus $E$. coli tRNA.

Construction and source of recombinant clones. The construction of the 5'DBH-CAT promoter-reporter plasmids has been previously described (Shaskus et al., 1992). To mutate the potential homeodomain binding sites, oligonucleotides were synthesized containing 7 base or 14 base mutations in the DB 1 regulatory element. The sequence of the 
oligonucleotides used to give rise to the mutations described in Figure 5, are 5'CTCCCCTAATTGACATCTCGAGCGCATGGACATCATC (M1), 5'TGCTCCGATCCTCCCTAGGCCTACACTAATGACGCAT (M2) and 5'CACTTTGCTCCGATCCTCCCTAGGCCTACATCTCGAGCGCATGGACATCATCAAGAG (M3), with underlined sequence representative of the mutations. These oligonucleotides correspond to the reverse complement of the DBH promoter proximal sequences. Oligonucleotide-directed mutagenesis was performed on plasmid $5^{\prime} \mathrm{DBH}$ CAT $(-232 /+14)$ using the Sculptor in vitro mutagenesis system (Amersham), according to the recommended procedures.

The GST-Arix fusion protein was constructed by cloning the original Arix DB1BP cDNA. comprising Arix2 sequence beginning at base 163, into the bacterial expression vector pGEX $2 \mathrm{~T}$. Insertion of the cDNA, excised from the vector with Eco R1, at the EcoR1 site of pGEX 2T produced an in-frame fusion protein between GST and Arix. The fusion protein was purified by glutathione-agarose affinity chromatography as described by Smith and Johnson (1988), with modifications described by Grieco et al. (1992).

\section{Results}

\section{Isolation of a $\mathrm{DBI}$ binding protein}

Previous studies of DBH gene expression led to the identification of the DB1 enhancer, present at bases -150 to -180 of the rat DBH promoter, which influences cell-type selective and second messenger response of the rat DBH gene (Shaskus et al., 1992). To identify the transcription factors interacting with this element, we screened a PC12 cell $\lambda$ gt 11 expression library with the DB1 enhancer sequence. The PC12 cell line is derived from a tumor of the rat adrenal medulla (Greene and Tischler, 1986). From 100,000 clones screened, 1 positive plaque was isolated, containing a cDNA insert of $1.2 \mathrm{~kb}$, named DB1BP (DB1 binding protein). This positive plaque was further purified, subcloned, and sequenced.

The amino acid sequence derived from the DNA sequence of DB1BP was used to search the GenBank/EMBL databanks. These analyses revealed that a segment of the cDNA contains extensive similarity to the paired and paired-like class of homeodomains, with amino acid identity to mouse Phox 2 (Valarche et al., 1993), and extensive homølogy to mouse Pax-3 (Goulding et al., 1991), Drosophila aristaless (al; Schneitz et al., 1993) and Prd (Bopp et al., 1986), Mhox (Cserjesi et al., 1992), and Phox (Gruenberg et al., 1992), which represent the same protein from mouse and human, rat cart-1 (Zhae et al., 1993), hamster Alx3 (Rudnick et al., 1994), and Smox-3, from the flatworm Schistosome (Webster and Mansour, 1992) (Fig. 1A). The presence of a glutamine, rather than a serine, residue at position 50 of the recognition helix places this homeodomain in the pairedlike class, rather than in the paired class, all of whose members contain a serine at that position (see Gehring, 1994).

Several cDNA libraries were rescreened with DB IBP with the goal of selecting a full length cDNA. Extensive screening of libraries produced at least three different classes of cDNAs. All cDNAs hybridizing to the original clone contain the same homeobox and $3^{\prime}$ terminal region, while the $5^{\prime}$ end immediately adjacent to the homeobox differs. Following the guidelines for naming homeobox genes after most similar Drosophila sequence (Scott, 1992), and noting that this represents a family of mRNA transcripts, we have named the cDNAs Arix, for the homology to the homeobox of Drosophila aristaless (Schneitz et al., 1993).

The full length sequence of one of the Arix cDNAs, with the derived amino acid sequence, is reported in Figure $1 B$. The 1610 base Arix 1 cDNA reported in Figure $1 B$ is $97 \%$ identical to Phox2, and thus represents the rat homolog of that transcript. Using 5' RACE, the 5' end of the cDNA was extended and cloned from PC12 cell mRNA, and contains an additional 169 bases from that reported for Phox 2 (Valarche et al., 1992). However, a putative initiator methionine followed by an open reading frame is not found in that region, so the predicted translational start site is the same as that designated for Phox 2 . The predicted size of Arix 1 protein is 29,500 Da.

A second region of amino acid similarity between that of the Arix 1 coding sequence and that of the prd and prd-like classes is the presence of the sequence lys-arg-lys immediately amino terminal to the beginning of the homeodomain. This short amino acid sequence is found in homeoproteins prd, al, Mhox, Smox3, and Pax-3. In addition to the homeodomain region, Arix 1 contains proline rich regions both $\mathrm{N}$ - and $\mathrm{C}$-terminal to the homeodomain. These regions are comprised of $21 \%$ and $42 \%$ proline respectively. Proline-rich regions are characteristic of several transcriptional activator proteins, including AP2 (Williams el al., 1988; Williams and Tjian, 1991), CTF/NF-1 (Mermod et al., 1989), and the homeodomain proteins prd (Bopp et al., 1986), Pax-3 (Goulding et al., 1991) and al (Schneitz et al., 1993). In addition, the 22 amino acid segment between residues and is comprised of $45 \%$ serine-threonine. Although Arix cDNAs contain a homeodomain similar to Pax-3, the paired box DNA-binding domain characteristic of Pax genes is not present, nor does the protein contain the octapeptide PRD repeat (see Gehring, 1993; Cai et al., 1994).

DNA sequence corresponding to the 5'-terminal region of a second class of Arix cDNA, named Arix 2 and representative of the original DBIBP, is presented in Figure $1 C$. The initial 132 bases are unique to this class of cDNA, while the subsequent sequence is identical. Two potential initiator methionine codons occur in this cDNA sequence, followed by an open reading frame. Neither ATG contains favorable flanking sequences for a functional translational initiation site, and Arix2 may not represent a full length cDNA.

\section{Distribution of Arix RNA transcripts}

The distribution of Arix RNA transcripts was evaluated by Northern blot and RNAse protection analyses. Using a cDNA probe comprising the common homeodomain and $3^{\prime}$ region, a major band of $1.7 \mathrm{~kb}$, accompanied by a minor band of $4.8 \mathrm{~kb}$, are observed in RN $\Lambda$ from the $\mathrm{PC} 12$ pheochromocytoma (Fig. $2 A$ ) and the catecholaminergic mouse CaTHa (Suri et al., 1993) cell lines (data not shown). Hybridization to total RNA extracted from several other tissues and cell lines was not observed. Hybridization with the ubiquitous cyclophilin probe validates the integrity of the RNA on the blot.

To increase the sensitivity of Arix RNA detection, we developed an RNAse protection assay. The probe used is derived from the $3^{\prime}$-end of the Arix cDNA, a region that is common to all of the different cDNAs. Using this RNAse protection assay, substantial expression is found in the sympathetic ganglia (Fig. $2 B$, lane 11), while lower levels of expression are found in the adrenal (Fig. 2B, lane 20). The low level of expression in the adrenal likely reflects the composition of the gland, where the DBH-expressing cells of the adrenal medulla represent only $10-15 \%$ of the mass, with the remainder the adrenal cortex. Expression of Arix mRNA is not observed in brain, nor in RNA extracted from a region of brain enriched in the noradrenergic locus ceruleus. Several noncatecholaminergic tissues were tested for the presence of Arix RNA transcripts, but all were negative.

As a measure for the sensitivity of our assay and the integrity of our RNA samples, we tested for the presence of the tyrosine 
A

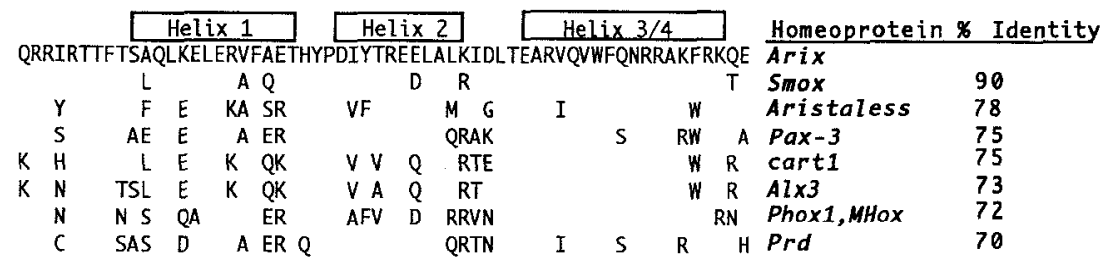

\section{$\mathbf{B}$}

CTTGCGTTGCACCGGGGCAंGAGTGCGGGCCGCGACGGGG̈GGGCGGACTCTCGGGCACTCAGAGTGGGTCTCAGGTCTTCTGCGCCTGGAGCTCGAAT

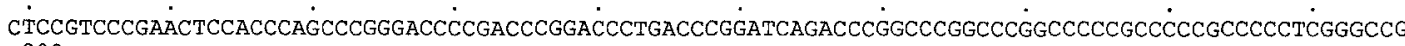

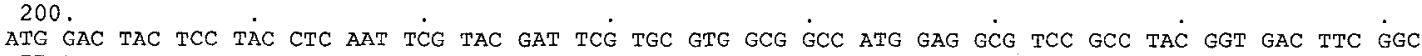
MET Asp Tyr Ser Tyr Leu Asn Ser Tyr Asp Ser CYS Val Ala Ala MET Glu Ala Ser Ala Tyr Gly Asp phe Gly 25 GCC TGC AGC CAG CCT GGA GGC TTC CAA TAC AGT CCC CTG CGG CCT GCC TTT CCC GCC GCG GGG CCA CCG TGC CCC Ala Cys Ser Gln Pro Gly Gly Phe Gln Tyr Ser Pro Leu Arg Pro Ala phe Pro Ala Ala Gly Pro pro Cys Pro GCG CTC GGC TCC TCC AAC TGT GCG CTT GGC GCC CTA CGC GAC CAC CAA CCC GCA CCC TAC TCG GCA GTT CCC TAC GLa leu Gly Ser Ser Asn Cys Ala Leu Gly Ala Leu Arg Asp His Gln Pro nla Pro Tyr Scr Ala val Pro Tyr
Ala AAG TTC TTC CCG GAG CCG TCC GGC CTG CAT GAG AAG CGC AAG CAG CGG CGGC ATC CGC ACंC ACG TTC ACG AGT GCT Lys Phe Phe Pro Glu Pro Ser Gly leu His Glu Lys Arg Lys Gln Arg Arg Ile Arg thr Thr Phe Thr Ser Ala 100 CAG CTC AAG GAG TTG GAG CGC GTC TTC GCC GAG ACC CAC TAC CCG GAC ATT TAC ACT CGT GAG GAA CTG GCG CTC Gln Leu Lys Glu Leu Glu Arg Val Phe Ala Glu Thr His Tyx Pro Asp Ile Tyr Thr Arg Glu Glu Leu Ala Leu 125

AAG ATC GAC CTC ACT GAG GCT CGC GTG CAG GTC TGG TTC CAG AAC CGC CGG GCT AAG ITC CGC AAA CAG GAG CGC Iys Ile Asp Leu Thr GIu Ala Arg Val Gln Val Trp Phe Gln Asn Arg Arg Ala Lys Phe Arg Lys Gln Glu Arg 150 GCG GCC ACG GCC $\dot{A} A A$ GGC GCG GCG GGA GCG ACG GGC GCC AAA AंAG GGC GAG GCG CGT TGC TCG TCG GAG GAC GAC Ala Ala Thr Ala Lys Gly Ala Ala Gly Ala Thr Gly Ala Lys Lys Gly Glu Ala Arg Cys Ser Ser Glu Asp Asp 175 GAC TCC A.AG GAG TCC ACG TGC AGC CAC $\dot{A} C G$ CCC CAC $\triangle \dot{A G C}$ ACC GCC TCG CंTC CCG CCC CC் CCG CCC CCA CCC AGC Asp Ser Lys Glu Ser Thr Cys Ser His Thr Pro Asp Ser Thr Ala Ser Leu Pro Pro Pro Pro Pro Ala Pro Ser 200

CTG GCC AGC CCG CTC CTG AGC CCC AGC CCT CTG CCC GCC GCG CTG GGC TCC GGG CCC GGG CCC CAG CCA CTC AAA Leu Ala Ser Pro Leu Leu Ser Pro Ser Pro Leu Pro Ala Ala Leu Gly Ser Giy Pro Gly Pro Gin pro Leu Lys 225 900.

GGC GCG TTG TGG GCA GGG GTG GCG GGC GGT GGG GGT GGC GGG CCC GGC AंCG GGC GCA GCA GAG CTG CTT AAG GCC GJy Ala Leu Trp Ala Gly Val Ala Gly Gly Gly Gly Gly Gly Pro Gly Thr Gly Ala Ala glu Leu Leu Lys Ala 250 TGG CAG CCG GCG GAA CCC GGA CCA GGT CCC TTC TCT GGA GTT CंTG TCC TCC TTT CAC CGG AÁ CCC GGT CCC GCC Trp Gin Pro Ala Glu Pro Gly Pro Gly Pro phe Ser Gly Val Leu Ser Ser phe His Arg Lys Pro Gly Pro Ala 275

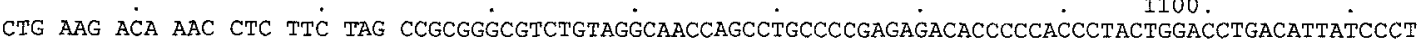
Leu Lys Thr Asn Leu Phe

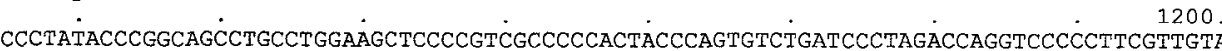
CCCTATACCGGCAGCCTGCCIGGAAGCTCCCCGTCGCCCCCACTACCCAGTGTCIGATCCCTAGACCAGGTCCCCCTTCGTTGTAAAACAAGCCAGGGC . . . . . . 1300 . CACTCTCGTCTGGAGTACTAATCACCAGGACCCCCCTCCAGGGCAGCGGAAGCCCTTTCTTGCTAGGCTTCCTTAGGAGCAGGGATCAAATTGCACCTGT CCCTA AGTCCCACCGCTAATCCCACCCTAACं GAGTCACCTCCCTTCCCTAGCCAGTATGTCGCAGAGATTÁACACTAGAGGGGAAGAGCTGTCGGGGAACGGAA CAAAGTGGTTCCTTCO. 1600 AAAAAAAAAAAAAAA

Figure 1. Sequence analysis of DB1 binding proteins. A, DB1BP encodes a homeobox protein. The sequence of the homeobox region of the DB1BP cDNA is compared to homeodomains of other proteins. $B$, Sequence of Arix 1 . The complete nucleotide sequence and derived amino acid sequence of Arix 1 is shown. The homeobox region is underlined. $C$, A schenatic diagran of domain of Arix 1, as defined by amino acid sequence and composition, is presented. $D$, Sequence of Arix 2 . The partial sequence of Arix 2 is shown. Following amino acid residue 83 the homeodomain begins, and the remainder of the cDNA is the same as Arix1. The original DB1BP sequence begins at nucleotide residue 163 of Arix2.

hydroxylase (TH) RNA transcript in these same RNA preparations. TH RNA was detected in appropriate tissues, including the brain nucleus locus ceruleus, adrenal and the midbrain (Fig. $2 C$ ). The lack of a signal in the brainstem region may represent a dilution of the small nuclei of $\mathrm{TH}$ cells below the level of sensitivity.

To assay specifically for the presence of the Arix 1 form of RNA in noradrenergic cells and tissues, an antisense RNA probe was prepared from the region containing the junction between the common and unique regions of the Arix 1 cDNA. In PC12 cells, adrenal and sympathetic ganglia, the size of the protected band spans both common and unique sequence (Fig. 2D), indicative of the presence of the Arix 1 transcript. In addition, these data demonstrate the presence of Arixl in sympathetic ganglia at prenatal gestation day E18.

These analyses of Arix RNA distribution exhibit a pattern of expression restricted to noradrenergic-derived tissues and cell lines. In the animal, expression of Arix RNA is observed only in the PNS and adrenal gland. These results are in agreement with those found for Phox2 (Valarche et al., 1993), with the exception of our observation that Arix 1 is expressed in adult sympathetic ganglia. 


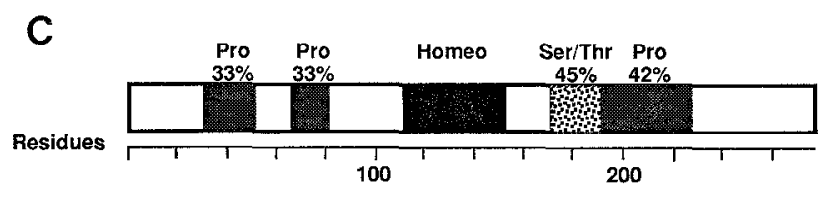

D

AAA AGT AGT TGC TCT TTT TCT CCT GAA GCT GCT TCA TTT GAA CAG AGA GCA GTA Lys Ser Ser Cys Ser phe Ser pro Glu Ala Ala Ser phe Glu Gln Arg Ala Val

81

108

ACT TGG ATC AGC CTC CGC CTA CAA AGG CAG CCA GAT GGA AGA CTT CAC GGA CTT Thr Trp Ile Ser Leu Arg Leu Gln Arg Gln Pro Asp Gly Arg Leu His Gly Leu

135

162

CAT CCT CTG ACT GCT CAC GGG CCG GGG CCG TAC TTA ATG CCG AAT CGG ATG CTC His pro Leu Thr Ala His Gly Pro Gly pro Tyr Leu MET Pro Asn Arg MET Leu

189

216

AGG CGC AGA AGA CCT GAG ACC CAC TCT GAG TGC CCG AGA GTC CGC CCG CCC CGT Arg Arg Arg Arg pro Glu Thr His Ser Glu Cys Pro Arg Val Arg Pro Pro Arg

Figure 1. Continued.

\section{Binding specificity of the Arix homeodomain}

In order to assess the region of the $\mathrm{DBH}$ DB1 enhancer that interacts with the Arix homeodomain, the DB1BP cDNA was cloned into the glutahione S-transferase (GST) bacterial expression system (Smith and Johnson, 1988). The GST gene is under the control of the inducible tac promoter, enabling overexpression of GST in bacterial culture. In this system, the Arix polypeptide was expressed as a fusion protein with GST. When cultures were induced, the GST-Arix fusion protein was expressed, and the fusion protein was purified.

The purified GST-Arix protein was evaluated for the ability to bind to the ${ }^{32} \mathrm{P}-\mathrm{DB} 1$ enhancer (Fig. 3A) using an electrophoretic mobility shift assay (EMS $\Lambda$ ). Major and minor DB1-Arix DNA-protein complexes are observed, both of which are competed by the presence of excess DB1 oligonucleotide (Fig. $3 B$, lane WT). To define the Arix binding site, oligonucleotides were synthesized with a mutation in the two putative homeodomain binding sites, characterized by the homeodomain binding core ATTA (Fig. 3A; see Gehring et al., 1994). When these oligonucleotides were used as competitors in the EMSA reaction, it was found that mutation of either core homeodomain binding site alone reduced the hinding efficiency, while mutation of both binding sites abolished the ability of the oligonucleotide to compete with the wild type sequence for binding (Fig. 3B). Neither of the single site mutant oligonucleotides could completely compete for binding, even at high competitor concentrations, suggesting that the presence of two intact sites on the DB1 oligonucleotide stabilizes Arix binding. Similarly, when wild type and mutant DB1 oligonucleotides were use as probes, the mutation of a single ATTA binding site reduced the extent of GST-Arix binding, while mutation of both binding sites eliminated binding (Fig. $3 C$ ). These results demonstrate the presence of two binding sites for the Arix homeodomain protein within the DB1 enhancer. The major band observed on the EMSA with the wild type DB1 sequence represents binding of GST-Arix to a single site, while the minor, slower migrating band is likely to represent occupation of both binding sites.

The ability of the mutant oligonucleotides to compete for binding of proteins from PC12 cell extracts was also investigated. Incubation of ${ }^{32} \mathrm{P}-\mathrm{DB} 1$ oligonucleotide with $\mathrm{PC} 12$ nuclear extract resulted in the formation of several complexes (Fig. 4A). Mutation of each ATTA site alone eliminates the ability of the oligonucleotide to compete for specific complexes, suggesting that the composition of the proteins bound to the ATTA sites is not identical. Mutation of both sites abolishes the ability of the oligonucleotide to compete for binding of all DBI-protein complexes, indicating that all proteins bound to the DBI oligonucleotide are interacting with the two homeodomain binding sites.

The complexes bound to wild type and mutant oligonucleotides were further characterized by performing EMSA with PC12 cell nuclear extracts using the mutant oligonucleotides as probes. Mutation of the left ATTA site eliminates the formation of DNA-protein complex 4, while mutation of the right site eliminates complexes 2 and 3 (Fig. 4B). Mutation of both ATTA sites removes the formation of all complexes that co-migrate with those formed with wild type DB1 sequence. These results 
$123 \quad 3 \quad 4 \quad 5$

A

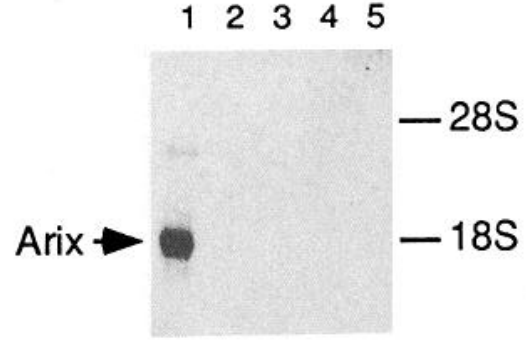

Cyclophilin -
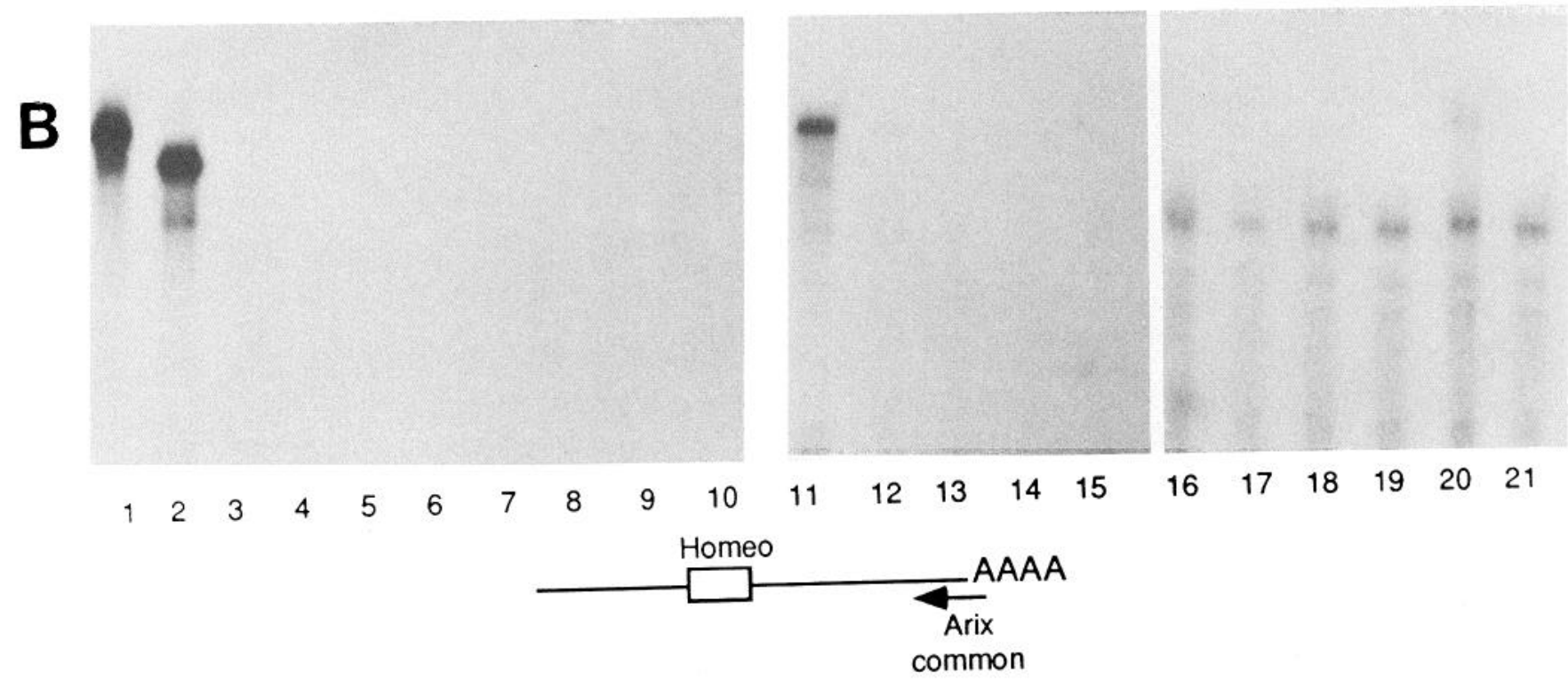

C
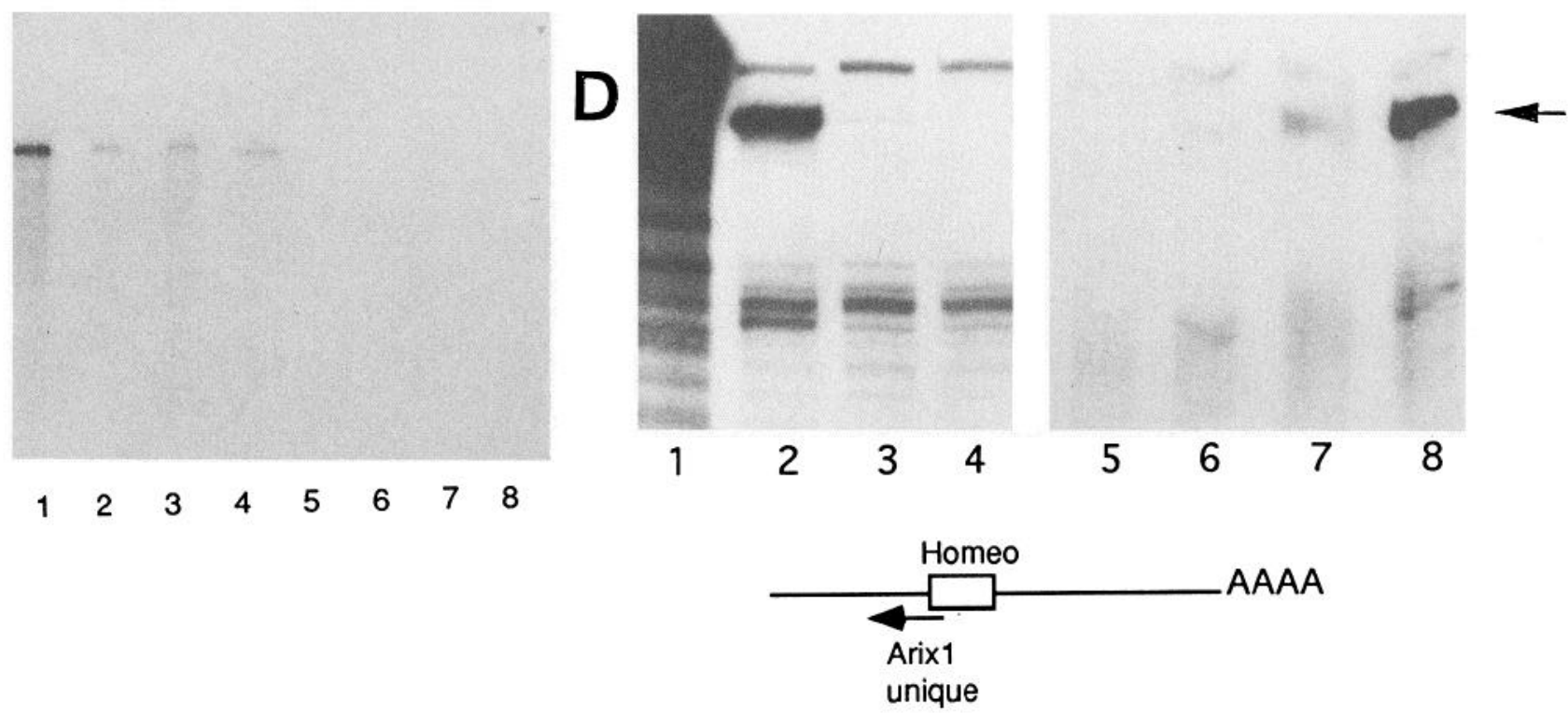

Figure 2. Analysis of the tissue distribution of Arix RNA. A, Northern blot analysis of Arix RNA transcripts; $10 \mu \mathrm{g}$ of total cellular RNA was added to each lane. Blots were hybridized first with Arix DNA probe, and subsequently hybridized with probe to the ubiquitous cyclophilin. Lanes 
complement those of Higure $4 A$, in that they demonstrate that the composition of nuclear proteins interacting at each ATTA site is specific for that site.

\section{Mutations of the homeodomain binding site influence basal DBH promoter activity}

The same mutations that were created to characterize the homeodomain protein binding sites on the DB 1 regulatory element were incorporated into a region of the $\mathrm{DBH}$ promoter in $5^{\prime} \mathrm{DBH}$ CAT $(-232 /+14)$, a promoter-reporter plasmid originally used to define the DB1 enhancer. These 5'DBH-CAT constructs were used to evaluate the consequence of mutations in the homeodomain binding site on basal promoter activity. Each construct was transfected into PC12 cells, along with a RSV-luciferase standard for transfection efficiency, and the CAT reporter gene activity was measured (Fig. 5). The results indicate that mutation of each binding site alone causes a partial, approximately $50 \%$, reduction in $5^{\prime} \mathrm{DBH}$ promoter activity, while the double mutant exhibits greater reduction in reporter gene activity.

\section{The Arixl homeodomain protein influences $D B H$ promoter activity}

To evaluate the ability of the Arix proteins to act as transcriptional modulators of DBH promoter activity, the full length Arix 1 cDNA was cloned into an expression vector where cDNA transcription is under the control of Rous sarcoma virus (RSV) promoter and enhancer elements. This RSV-Arix 1 expression plasmid was then cotransfected with the 5'DBH-CAT $(-230$ / +14 ) reporter plasmid into both the Arix-positive PC12 pheochromocytoma cell line and the Arix-negative HepG2 hepatoma cell line, along with an RSV-luciferase plasmid to monitor transfection efficiency. When cell extracts were analyzed for reporter gene activity, it was found that Arix 1 caused a modest 1.7-fold stimulation of $\mathrm{DBH}$ promoter activity in PC12 cells (Fig. 6A), while a fourfold reduction in reporter gene activity was observed in the HepG2 cell line (Fig. 6B). Similar results were found when the DB1(2)-TK-CAT construct containing two copies of DB1 adjacent to the TK promoter, was cotransfected with Arix 1 (data not shown). It is probable that the modest effect of Arix 1 in the PC12 cell line is due to the presence of endogenous Arix 1 in these cells, which contributes to background levels of expression.

The influence of Arix1 on the tyrosine hydroxylase promoter and $5^{\prime}$ flanking sequences was evaluated by cotransfecting the 5'TH CAT $(-773 /+27)$ plasmid with RSV-Arix1 into HepG2 cell cultures. In the presence of RSV-Arix1, a threefold stimulation of TH promoter activity was observed (Fig. $6 B$ ). No effect of Arix on TH promoter activity was observed when cotrans- fected into $\mathrm{PC} 12$ cells. 'The stimulatory effect of Arixl on the $\mathrm{TH}$ promoter demonstrates a differential regulatory activity of Arix 1 on the TH and DBH promoter proximal regions. The observation that Arix 1 stimulates transcription from the TH promoter at the same concentrations at which neutral or inhibitory effects are seen on the DBH promoter suggests that the inhibitory effect of Arix 1 on $5^{\prime} \mathrm{DBH}-\mathrm{CAT}$ is not due to squelching.

The region of the $\mathrm{TH}$ promoter exhibiting the most similarity to the Arix binding sites of DB1 is found in the Oct/Hept domain corresponding to bases -175 to -158 of the rat TH gene (Cambi et al., 1989; Yoon and Chikaraishi, 1992). The reverse complement of this sequence exhibits $82 \%$ homology to the DB1 regulatory element in the region of the Arix binding sites (Fig. $6 C$ ). To test the capacity of Arix to bind to the TH Oct/Hept region, an oligonucleotide corresponding to bases -156 to -176 was used as a probe in the EMSA, with GST-Arix. The TH sequence does interact with GST-Arix, and the DNA-protein complex is competed both by the TH and DB1 oligonucleotides. These results identify an Arix binding site in the TH promoter proximal region.

\section{Discussion}

The primary goal of this study was to further understand the specificity of DBH gene expression through the identity of transcription factors that interact with the DB1 regulatory element of the rat DBH gene. The DB1 element exhibits regulatory prop erties in a cell type selected pattern and also mediates a response to the protein kinase $\mathrm{A}$ and $\mathrm{C}$ systems. Our research has led to the identification of the Arix family of homeodomain-containing transcription factors. The Arix mRNA transcripts are restricted to the noradrenergic tissue of the PNS and adrenal in adult rats, as well as cell lines derived from these sources. During development, the mouse homolog of Arix1, Phox2, is detected in the sympathetic ganglia primordium at E10 (Valarche et al., 1993) prior to the onset of DBH RNA expression at F1.3.5 (Cochard et al., 1978). Phox 2 is also observed in the immature locus cereuleus at E13.5, although our results do not detect Arix in adult locus ceruleus. The pattern of expression of these transcripts, plus the presence of the homeodomain, suggest that this family of proteins may be involved in the specificity of expression of the catecholamine biosynthetic genes, and in the selection of the noradrenergic neurotransmitter phenotype. The continued postnatal expression of Arix RNA in the sympathoadrenal lineage, while not present in the brainstem noradrenergic tissue, may reflect the plasticity of phenotype of the neural crest derived cells (Anderson et al., 1993). Prolonged expression Arix in cells of the sympathoadrenal lineage may be necessary to maintain the noradrenergic phenotype.

\section{$\leftarrow$}

represent rat RNAs extracted from: 1 , PC12 cells; 2, adrenal; 3, midbrain; 4, brain cortex; 5, brainstem. $B$, RNase protection analysis of Arix RNA transcripts; $10 \mu \mathrm{g}$ of total RNA from all tissues except PC12 and superior cervical ganglia, which contained $5 \mu \mathrm{g}$ and $3 \mu \mathrm{g}$, respectively, was incubated with ${ }^{32}$ P-riboprobe corresponding to 300 bases of the $3^{\prime}$ end of the cDNA. Following hybridization, nonhybridized RNA was digested with RNAses, and the protected RNAs were separated by electrophoresis on $6 \%$ polyacrylamide/8 M urea gels. Lane 1 represents undigested probe, and is longer than the protected hybridization band because of the presence of vector sequences. Other lanes represent RNAs extracted from: 2 , PC12; 3, brainstem; 4 , brain cortex; 5 , midbrain; 6 , brain locus ceruleus; 7 , heart; 8 , lung: 9 , testis; 10 , tRNA; 11 , sympathetic superior cervical ganglia; 12, CaTHa cells; 13, C6 glioma; 14, rat 1 cells; 15, hepatoma H4; 16, heart; 17, testis; 18, lung; 19, kidney; 20, adrenal; 21, liver. The samples presented were derived from three different experiments. The faster migrating bands present in lanes $16-21$ represent nonspecific background. $C$, RNAse protection of tyrosine hydroxylase transcripts. $10 \mu \mathrm{g}$ of total RNA from all tissues except PC12 were incubated with ${ }^{32} \mathbf{P}$ riboprobe corresponding to bases $1520-1240$ of TH cDNA. Lanes represent RNA samples from the indicated tissues: 1, brain locus ceruleus; 2 , adrenal; 3, adrenal; 4, midbrain; 5, brainstem; 6 , brain cortex; 7, heart; 8 , liver. $D$, RNase protection of Arix 1 transcripts. A riboprobe representing the junction between the common and unique scquenec was used to detect specific Arix 1 transcripts. Each sample contained $10 \mu \mathrm{g}$ of total RNA expect for those from the superior cervical ganglia, which contained $2 \mu \mathrm{g}$. Lane 1 represents undigested probe. Other lanes represent RNAs from: 2, PC12 cells; 3, adrenal; 4, tRNA; 5, Ca77 cells; 6, adrenal; 7, adult ganglia; 8 , e18 ganglia. 

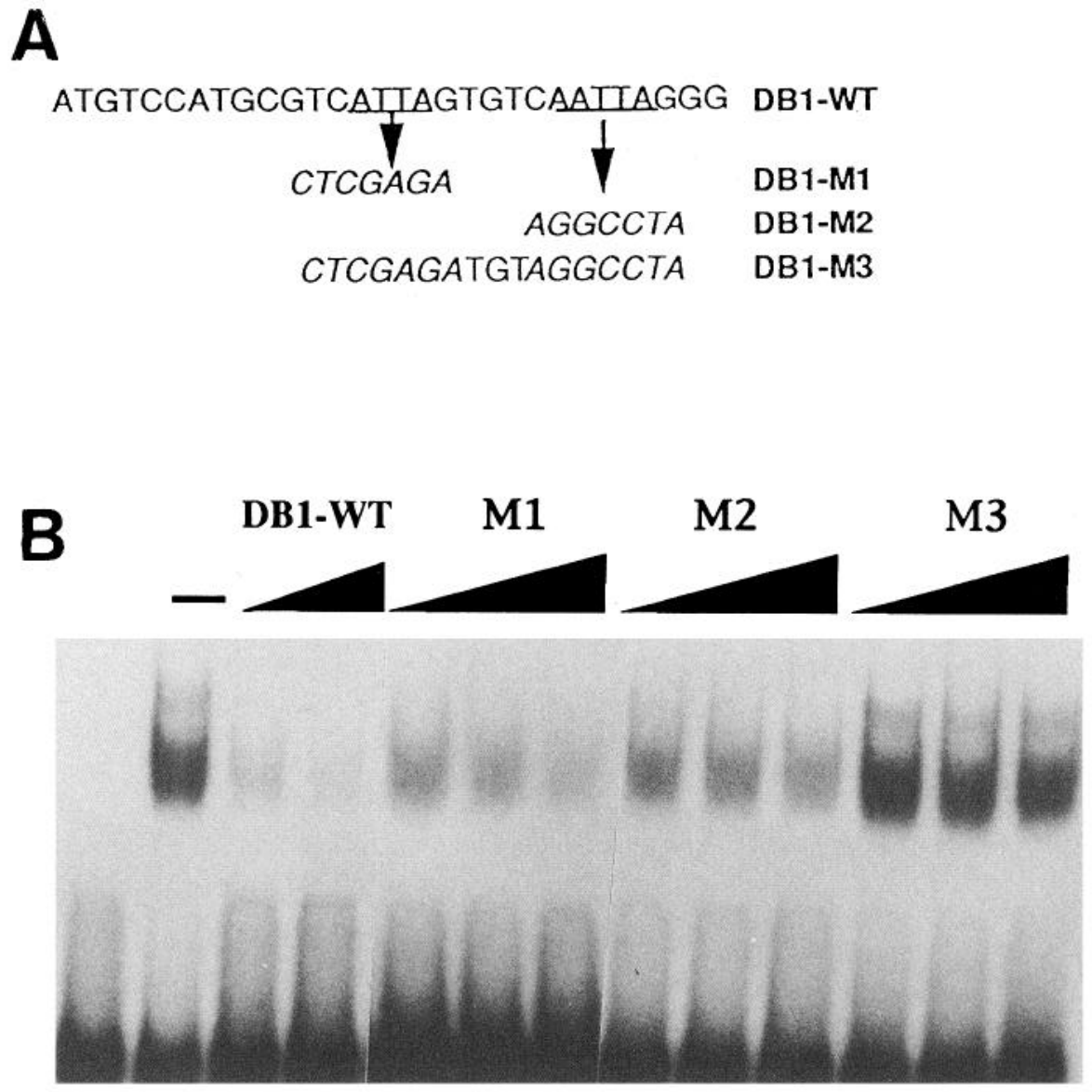

Figure 3. EMSA analysis of DB1 binding to the Arix homeodomain. A, Mutations in the DB1 oligonucleotide were made in the putative homeodomain protein recognition site, characterized by an ATTA core, underlined. $B$, EMSA of DB1 enhancer and GSTArix fusion protein. The double stranded DB1 oligonucleotide was labeled with ${ }^{32} \mathrm{P}$ and incubated with GST-Arix fusion protein. Incubations contained indicated competitor oligonucleotides at 200,400 , and $600 \mathrm{ng}$. Complexes were separated by electrophoresis in $6 \%$ polyacrylamide gels. Purified GST protein does not bind DB1 oligonucleotide (data not shown). $C$, EMSA of DB1-WT and mutant oligonucleotides and GST-Arix fusion protein. DB1-WT and mutant oligonucleotides were each radiolabeled with ${ }^{32} \mathrm{P}$ and incubated with GST-Arix fusion protein.

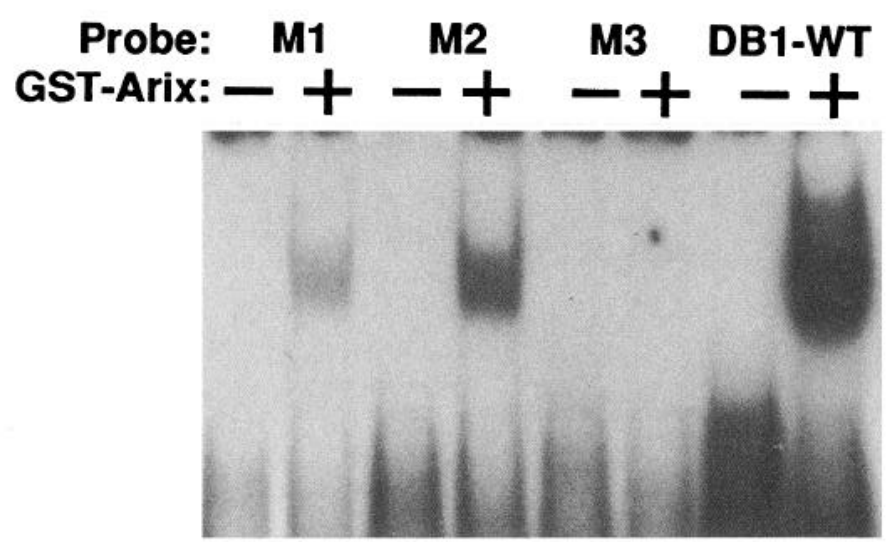

Experiments focused upon defining the binding site for Arix within the DB1 enhancer have demonstrated the presence of two binding sites, with the core ATTA separated by 6 bases. The results from the EMSA demonstrate that each of these sites interacts independently with the Arix homeodomain, in that mutation of either site reduces, but does not eliminate, the total binding on the DB1 enhancer. Similar results were observed when the influence of the Arix binding sites on $\mathrm{DBH}$ promoter activity were evaluated by transfection into PC12 cells. A mutation in either site reduced DBH promoter activity by approximately $50 \%$, while mutation of both sites reduced activity to a level that is approximately the sum of either site alone. Studies using the mutant oligonucleotides demonstrate that each binding site competes very poorly for binding to the adjacent site, in that oligonucleotides containing a mutation in one site failed to efficiently compete for binding to the wild type DB1 oligonucle- 

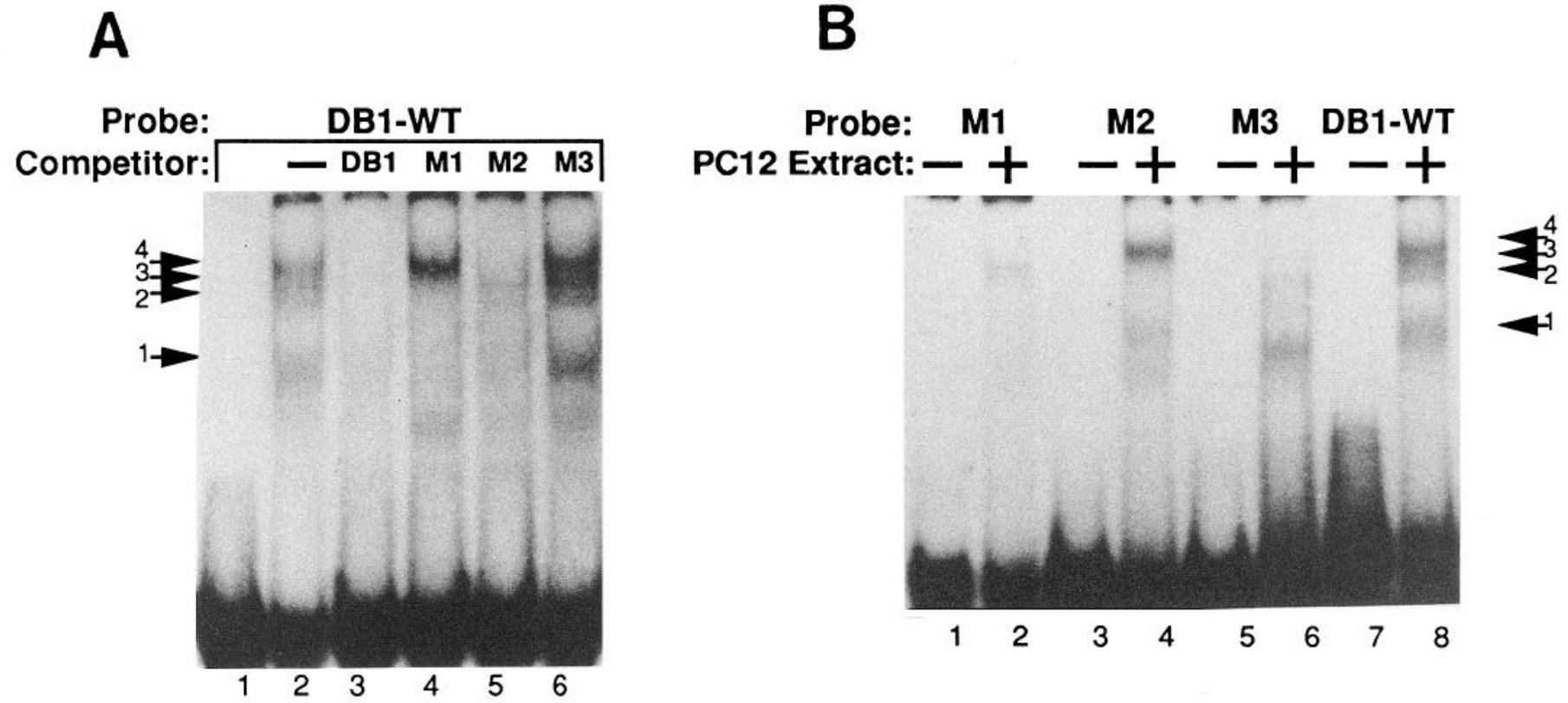

Figure 4. EMSA analysis of DB1 binding to PC12 nuclear proteins. A, DB1 oligonucleotide was labeled with ${ }^{32} \mathrm{P}$ and incubated with $3 \mu \mathrm{g}$ of nuclear extract from PC12 cells. Competitors were present at $200 \mathrm{ng}$. B, DB1-WT and mutant oligonucleotides were each radiolabeled with ${ }^{32} \mathrm{P}$ and incubated with $3 \mu \mathrm{g}$ of nuclear extract from PC12 cells.

otide, even at very high concentrations. Together, these results suggest that each Arix binding site contributes equally, and independently, to the activity of the DBH promoter. The independent contribution of each binding site on the DBH promoter is consistent with studies performed on the binding properties of prd class homeodomains. It was found that homeodomain binding sites that were palindromic and separated by $2-3$ bases bound cooperatively, but separation of the two sites by greater than 4 bases reduced the synergistic interaction (Wilson et al., 1993).

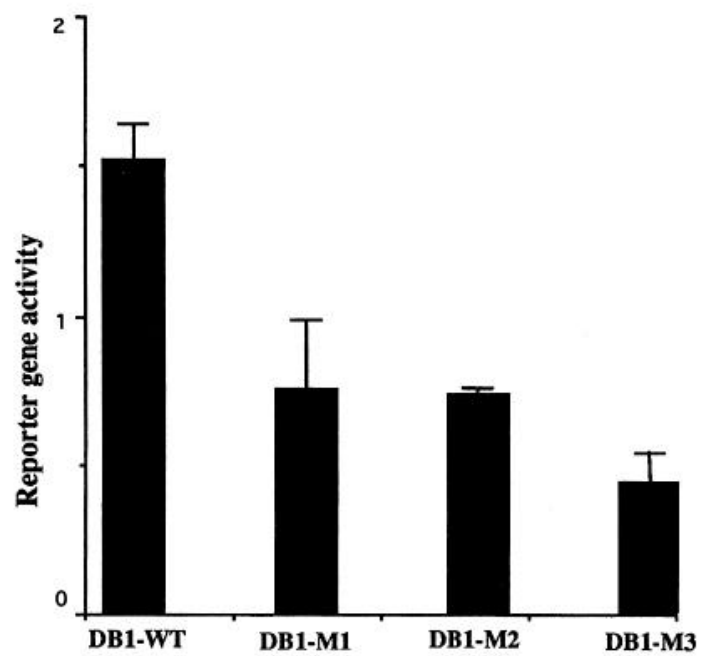

Figure 5. Mutations in the DB1 enhancer reduce DBH promoter activity. The same mutations as described in Figure $3 A$ were incorporated into the 5 'DBH-CAT $(-232 /+14)$ plasmid; $10 \mu \mathrm{g}$ of each plasmid was transfected into $\mathrm{PC} 12$ cell cultures and analyzed for CAT reporter gene activity. All cultures were cotransfected with $2 \mu \mathrm{g}$ of RSV-luciferase as a monitor of transfection efficiency, and values are standardized to luciferase activity. The results presented are the mean $\pm \mathrm{SE}$ of three independent samples.
The EMSA with PC12 cell extracts suggest that all nuclear proteins bound to the DB1 enhancer and resolved by the EMSA are interacting at or near one of the two homeodomain sites. This conclusion is derived from the observation that the M3 oligonucleotide, with mutations in both sites, is unable to compete for DNA-protein complex formation in the EMSA. The competition studies with oligonucleotides containing mutations in a single Arix binding site agree with this conclusion, and further suggest that the composition of the DNA-protein complexes are not identical at each binding site. The selective competition of specific DNA-protein complexes by each single site oligonucleotide suggest that each site contains a unique recognition sequence, and that multiple proteins contribute to the ability of these sites to influence DBH promoter activity. In the study where the DB1 enhancer was initially defined, we suggested that the CRE-like site, TGCGTCA, was a likely candidate for the regulatory element contributing to both basal and second messenger induced transcription of the DBH gene (Shaskus et al., 1992). Studies performed with the human DBH gene have shown that a construct containing an internal deletion of a 13 base sequence containing the human cAMP response element (CRE), TGACGTCC, leaving the conserved Arix binding site intact, resulted in both reduction of basal activity and loss of cAMP induced transcriptional regulation (Ishiguro et al., 1993; Kim et al., 1994). A CRE element is important for maintaining the specificity of basal promoter activity for several genes, including tyrosine hydroxylase (Kim et al., 1993). The observation that all proteins in PC12 cell extracts that bind to the DB1 enhancer are interacting at either of the Arix binding sites shift the focus of the critical region of the DB1 regulatory element from the putative CRE to the homeodomain binding region, and suggest that second messenger regulation and the specificity of basal promoter activity are regulated at separate sites in the rat DBH gene. Nonetheless, the data demonstrating that mutation of both homeodomain binding sites reduces basal promoter activity to 

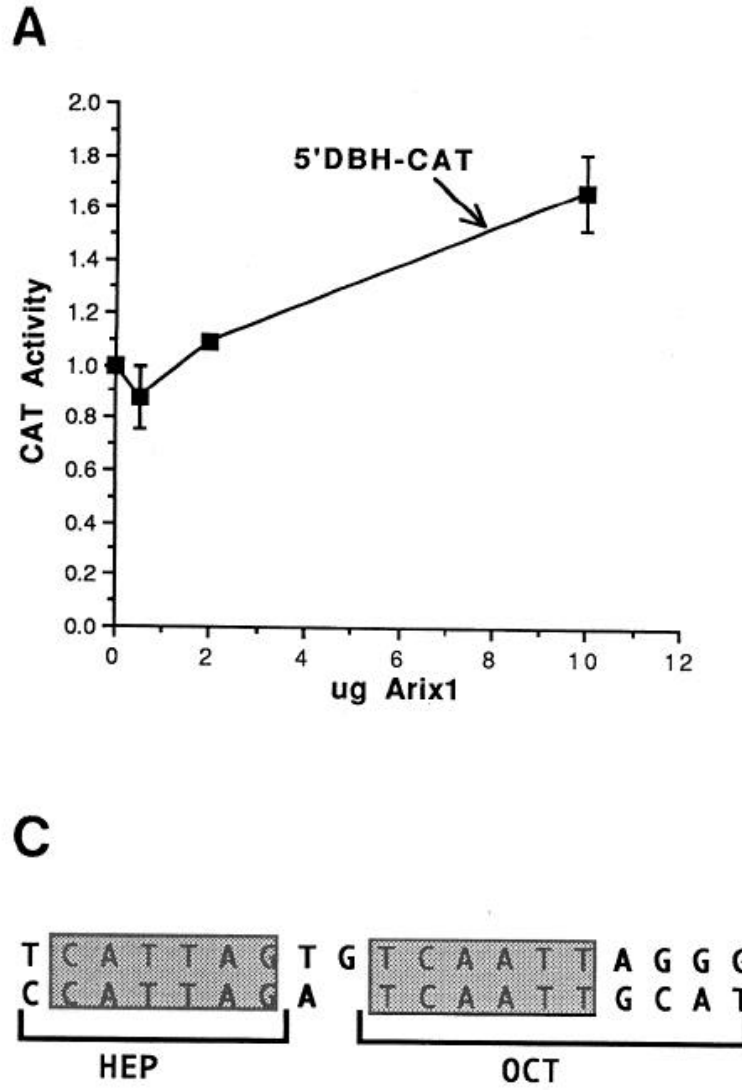
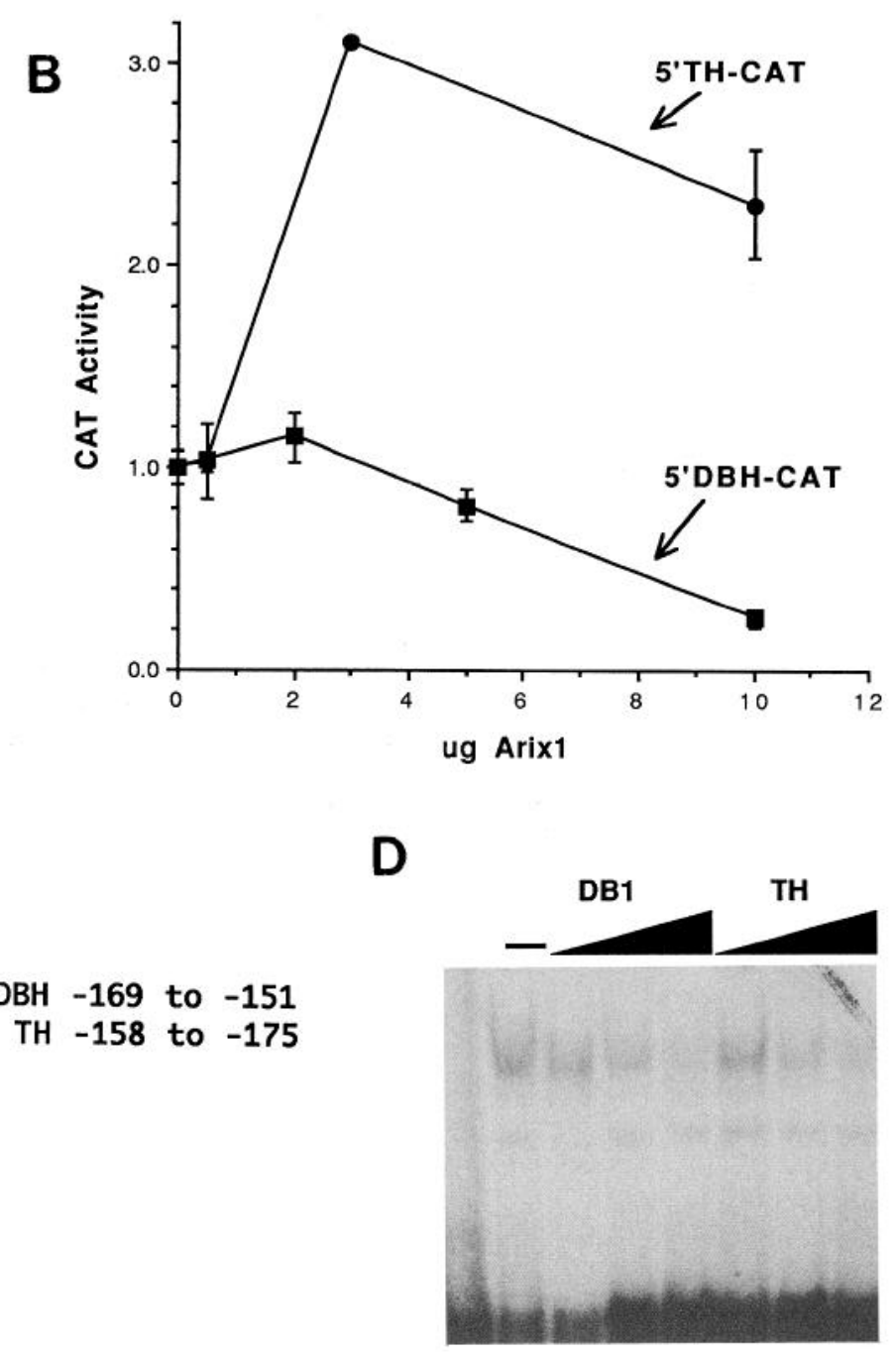

Figure 6. Arix 1 influences transcription from the DBH promoter regions. A, $0.5-10 \mu \mathrm{g}$ of RSV-Arix 1 , or vector SPRSV, plus $10 \mu \mathrm{g}$ of 5 'DBHCAT $(-230 /+14)$, were cotransfected into either PC12. All cultures were cotransfected with $2 \mu \mathrm{g}$ of RSV-luciferase as a monitor of transfection efficiency. Values for CAT activity are standardized to protein, rather than luciferase activity, because transfected Arix produced a 2-2.5-fold stimulation of luciferase activity. Values represent CAT activity relative to the promoter activity with the SPRSV vector control. The results presented are the mean \pm SE of three to nine independent samples, derived from three different experiments. $B, 0.5-10 \mu g$ of RSV-Arix 1, or SPRSV, plus $10 \mu \mathrm{g}$ of $5^{\prime} \mathrm{TH}-\mathrm{CAT}(-773 /+27)$ or 5'DBH-CAT $(-230 /+14)$, were cotransfected into HepG2 cells. All cultures were cotransfected with $2 \mu \mathrm{g}$ of RSV-luciferase as a monitor of transfection efficiency. Values for CAT activity are standardized to luciferase activity. The results presented are the mean $\pm \mathrm{SE}$ of three to six independent samples, derived from three different experiments. $C$, The Oct/Hept region of the TH promoter contains extensive similarity with the Arix binding sites of the DB1 enhancer. The similar nucleotide sequence suggests that Arix1 may be influencing TH promoter activity at this site. $D$, The Oct/Hep region of the TH promoter interacts with Arix. An oligonucleotide corresponding to bases -156 to -176 of the rat TH promoter was used as a probe in the EMSA, with GST-Arix as the potential binding protein. Increasing concentrations of indicated oligonucleotide competitors were added as indicated, at 100, 200, and $400 \mathrm{ng}$.

approximately $30 \%$ of wild type, but does not eliminate basal activity, suggests that other factors contribute to transcription from the $\mathrm{DBH}$ promoter. The possibility remains that factors bound to the AP2 site (Greco et al., 1995), the potential CRE beginning directly $5^{\prime}$ to the aforementioned DBH CRE/AP1 site (TGATGTCC), or as yet unindentified regulatory sites, contribute to basal DBH promoter activity. Whether these sites interact independently or synergistically has yet to be demonstrated.

The observation that transfection of Arix 1 into HepG2 cells caused inhibition of DBH promoter activity under the same conditions in which TH promoter activity is stimulated was unexpected in that we predicted Arix would function as a transcriptional activator of the DB1 regulatory element, originally defined as an enhancer. Conversely, the Hept/Oct region of the TH promoter region, containing an Arix binding site, has been shown to exert a negative regulatory effect in the PC8b cell line (Yoon and Chikaraishi, 1992), although a positive regulatory effect is observed in the non-catecholaminergic BHK cell line (Dawson et al., 1994). The differential effect of Arix 1 on the transcriptional activity of the TH and DBH genes demonstrates that Arixl can have opposite effects on transcription when bound to different promoter regions. In combination with the results from the EMSAs, these results suggest that Arix interacts with several cellular proteins, and the nature of the protein complex alters both the specificity of binding and the eventual influence on transcriptional activity from that promoter. Whether the effect of Arixl on transcription of the TH and DBH genes observed in HepG2 cells reflects the in vivo function of Arix 1 
remains to be determined, as the composition of nuclear cofactors is likely to differ between tissue types. In addition, it remains to be demonstrated that Arixl actually occupies those defined binding sites in the $\mathrm{TH}$ and $\mathrm{DBH}$ genes in vivo. The other gene shown to have Arixl binding sites, NCAM, is not directly regulated by transfection of Arix 1 into cell cultures (Valarche et al., 1993). However, Arix 1 partially prevents the negative transcriptional regulatory influence of another homeodomain protein, Cux, on the NCAM gene. Together, these results suggest that Arix may interact with several coregulators, with the binding specificity and final outcome on transcription dependent upon the composition of the protein complex.

The identification of this family of Arix cDNAs, with expression of RNA transcripts in noradrenergic tissue both during prenatal development and in the adult, suggests that Arix proteins may modulate the selection and maintenance of the cellular neurotransmitter phenotype. The pattern of expression suggests that these proteins may be specific for the sympathoadrenal lineage. Although homeodomain proteins are classically believed to exert their critical functions during embryonic development, the potential plasticity of the noradrenergic phenotype in vitro and in vivo (see Anderson, 1993) may require the presence of factors to maintain the expression of the $\mathrm{TH}$ and $\mathrm{DBH}$ genes in the adult. The Arix family of homeodomain proteins represents candidate factors to modulate cellular neurotransmitter identity.

\section{References}

Anderson DJ (1993) Molecular control of cell fate in the neural crest: the sympathoadrenal lineage. Annu Rev Neurosci 16:129-158.

Banerjee SA, Hoppe P, Brilliant M, Chikaraishi DM (1992) 5' Flanking sequences of the rat tyrosine hydroxylase gene target accurate tissuespecific, developmental, and transsynaptic expression in transgenic mice. J Neurosci 12:4460-4467.

Bopp D, Burri M, Baumgartner S, Frigerio G, Noll M (1986) Conser vation of a large protein domain the the segmentation gene paired and in functionally related gene of Drosophila. Cell 47:1033-1040.

Cai J, Lan Y Appel LF, Weir M (1994) Dissection of the Drosophila paired protein: functional requirements for conserved motifs. Mech Dev 47:139-150.

Cambi F, Fung B, Chikaraishi D (1989) 5' Flanking DNA sequences direct cell-specific expression of rat tyrosine hydroxylase. J Neurochem 53:1656-1659.

Chomczynski P, Sacchi N (1987) Single-step methhod of RNA isolation by acid guanidinium thiocyanate-phenol-cholorform extraction. Anal Biochem 162:156-159.

Cochard P, Goldstein M, Black IB (1978) Ontogenetic appearance and disappearance of tyrosine hydroxylase and catecholamines in the rat embryo. Proc Natl Acad Sci USA 75:2986-2990.

Cserjesi P, Lilly B, Bryson L, Wang Y, Sassoon DA, Olson EM (1992) MHox: a mesodermally restricted homeodomain protein that binds an essential site in the muscle creatine kinase enhancer. Development 115:1087-1101.

Dawson SK, Yoon SO, Chikaraishi DM, Lillycrop KA, Latchman DS (1994) The Oct-2 transcription factor represses tyrosine hydroxylase expression via a heptamer TAATGARAT-like motif in the gene promoter. Nucleic Acids Res 22:1023-1028.

de Wet JR, Wood KV, DeLuca M, Helinski DR, Subramani S (1987) Firefly luciferase gene: structure and expression in mammalian cells. Mol Cell Biol 7:725-737.

Dignam JD, Lebovitz RM, Roeder RG (1983) Accurate transcription initiation by RNA polymerase II in a soluble extract from isolated mammalian nuclei. Nucleic Acids Res 11:1475-1474.

Fung BP, Yoon SO, Chikaraishi DM (1992) Sequences that direct rat tyrosine hydroxylase gene expression. J Neurochem 58:2044-2052.

Gehring WJ, Affolter M, Burglin (1994) Homeodomain proteins. Annu Rev Biochem 63:487-526.

Gizang-Ginsberg E, Ziff EB (1990) Nerve growth factor regulates tyrosine hydroxylase gene transcription through a nucleoprotein complex that contains c-Fos. Genes Dev 4:477-491
Gizang-Ginsberg E, Ziff EB (1994) Fos family members successively occupy the tyrosine hydroxylase gene AP-1 site after nerve growth factor or epidermal growth factor stimulation and can repress transcription. Mol Endocrinol 8:249-262.

Goulding MD, Chalepakis G, Deutsch U, Erseliu JR, Gruss P (1991) Pax-3, a novel murine DNA binding protein expressed during early neurogenesis. EMBO J 10:1135-1147.

Gorman CM, Moffat LF, Howard BH (1982) Recombinant genomes which express chloramphenicol acetyltransferase in mammalian cells. Mol Cell Biol 2:1044-1051.

Graham FL, van der Eb AJ (1973) A new technique for the assay of infectivity of human adenovirus 5 DNA. Virology 52:456-457.

Greco D, Zellmer E, Zhang Z, Lewis EJ (1995) Transcription factor AP- 2 regulates expression of the dopamine $\beta$-hydroxylase gene. $J$ Neurochem 65:510-516.

Greene L, Tischler AS (1976) Establishment of a noradrenergic clonal line of rat adrenal pheochromobytoma cells which respond to nerve growth factor. Proc Natl Acad Sci IJSA 73:2424-2428.

Grieco F, Hay JM, Hull R (1992) An improved procedure for the purification of protein fused with glutathione S-transferase. Biotechniques 13:856.

Grima G, Lamouroux A, Blanot F, Biguet NF, Mallet M (1985) Complete coding sequence of rat tyrosine hydroxylase mRNA. Proc Natl Acad Sci USA 82:617-621.

Grueneberg DA, Natesan S, Alexandre C, Gilman MZ (1992) Human and Drosophila homeodomain proteins that enhance the DNA-binding activity of serum response factor. Science 257:1089-1095.

Guillemot F, Lo L-C, Johnson JE, Auerbach A, Anderson DJ, Joyner AL (1993) Mammalian achaete-scute homolog-1 is required for the early development of olfactory and autonomic neurons. Cell 75:463476.

Herr W, Sturm RA, Clerc RG, Corcoran LM, Baltimore D, Sharp PA, Ingraham HA, Rosenfeld MG, Finney $M$, Ruvkin $G$, Horvitz HR (1988) The POU domain: a large conserved region in the mammalian Pit-1, Oct-1, Oct-2, and Caenorhabditis elegans unc-86 gene products. Genes Dev 2:1513-1515.

Hoyle GW, Mercer EH, Palmiter RD, Brinster RL (1994) Cell-specific expression from the human dopamine $\beta$-hydroxylase promoter in transgenic mice is controlled via a combination of positive and negative regulatory elements. J Neurosci 14:2455-2463.

Icard-Liepkalns E, Faucon Biguet N, Vyas S, Robert JJ, Sassone-Corsi P, Mallet J (1992) AP-1 complex and c-fos transcription are involved in TPA provoked and trans-synaptic inductions of the tyrosine hydroxylase gene: insights into long-term regulatory mechanisms. J Neurosci Res 32:290-298.

Ishiguro H, Kim KT, Joh TH, Kim K-S (1993) Ncuron-specific expression of the human dopamine $\beta$-hydroxylase gene requires both the cAMP-response element and a silencer region. J Biol Chem 268: $17987-17994$.

Johnson JE, Birren SJ, Anderson DJ (1990) Two rat homologues of Drosophila achaete-scute specifically expressed in neuronal precursors. Nature 346:858-861

Kim K-S, Lee MK, Carroll J, Joh TH (1993) Both the basal and inducible transcription of the tyrosine hydroxylase gene are dependent upon a cAMP response element. J Biol Chem 268:15689-15695.

Kim K-S, Ishiguro H, Tinti C, Wagner J, Joh TH (1994) The cAMPdependent protein kinase regulates transcription of the dopamine $\beta$-hydroxylase gene. J Neurosci 14:7200-7207.

Kobierski LA, Chu HM, Tan Y, Comb MJ (1991) cAMP-dependent regulation of proenkephalin by JunD and JunB: positive and negative effects of AP-1 proteins. Proc Natl Acad Sci USA 88:10222-10226.

Konradi C, Kobierski LA, Nguyen TV, Heckers S, Hyman SE (1993) The cAMP-response-element-binding protein interacts, but Fos protein does not interact, with the proenkephalin enhancer in rat striatum. Proc Natl Acad Sci USA 90:7005-7009.

Krumlauf R (1994) Hox genes in vertebrate development. Cell 78:191201.

Lamouroux A, Houhou L, Faucon Biguet N, Serck-Hanssen G, Guibert B, Icard-Liepkalns C, Mallet J (1993) Analysis of the human dopamine $\beta$-hydroxylase promoter: transcriptional induction by cyclic AMP. J Neurochem 60: 364-367.

Lo L, Johnson JE, Wuernschell CW, Saito T, Anderson DJ (1991) Mammalian achaete-scute homolog 1 is transiently expressed by spatially-restricted subsets of early neuroepithelial and neural crest cells. Genes Dev 5:1524-1537. 
Mermod N, O'Neill EA, Kelly TJ, Tjian R (1989) The proline-rich transcriptional activator of CTF/NF-I is distinct from the replication and DNA binding domain. Cell 58:741-753.

Rudnick A, Ling TY, Odagiri H, Rutter W, German MS (1994) Pancreatic beta cells express a diverse set of homeobox genes. Proc Natl Acad Sci USA 91:12203-12207.

Sambrook, J Fritsch EF, Maniatis T (1989) Molecular cloning: a laboratory manual. Cold Spring Harbor, NY: Cold Spring Harbor Laboratory.

Schneitz K, Spielmann P, Noll M (1993) Molecular genetics of aristaless, a prd-type homeo box gene involved in the morphogenesis of proximal and distal pattern elements in a subset of appendages in Drosophila. Genes Dev 7:114-129.

Scott MP (1992) Vertebrate homeobox gene nomenclature. Cell 71: $551-553$.

Shaskus J, Greco D, Asnai LP, Lewis EJ (1992) A bifunctional genetic regulatory element of the rat dopamine $\beta$-hydroxylase gene influenccs cell type specificity and second messenger-mediated transcription. J Biol Chem 267:18821-18830.

Shaskus J, Zellmer E, Lewis EJ (1995) A negative regulatory element in the rat dopamine $\beta$-hydroxylase gene contributes to the cell type specificity of expression. J Neurochem 64:52-60.

Singh H, Clerc RG, LeBowitz JH (1989) Molecular cloning of sequence-specific DNA binding proteins using recognition site probes. Biotechniques 7:252-261.

Smith DB, Johnson KS (1988) Single-step purification of polypeptides expressed in Escherichia coli as fusions with glutathione S-transferase. Gene 67:31-40.

Stachowiak MK, Gox A, Hong JS, Kaplan BB, Stachowiak EK (1991) Neural and hormonal regulation of the tyrosine hydroxylase gene in adrenal medullary cells: participtation of $\mathrm{c}$-fos and AP1 factors. Mol Cell Neurosci 1.

Suri C, Fung BP, Tischler AS, Chikaraiski DM (1993) Catecholamin- ergic cell lines from the brain and adrenal glands of tyrosine hydroxylase-sv40 $t$ antigen transgenic mice. J Neurosci 13:1280-1291.

Valarche I, Tissier-Seta JP, Hirsh M-R, Martinez S, Gordis C, Brunet I-F (1993) The mouse homeodomain protein Phox2 regulates Ncam promoter activity in concert with Cux/CDP and is a putative determinant of neurotransmitter phenotype. Development 119:881-896.

Webster PJ, Mansour TE(1992) Conserved classes of homeodomains in Schistosoma mansoni, an early bilateral metazoan. Mech Dev 38: $25-32$.

Weintraub H, Davis R, Tapscott S, Thayer M, Krause M, Benezra R, Blackwell TK, Turner D, Rupp R Hollenberg S, et al. (1991) The myoD gene family: nodal point during specification of the muscle cell lineage. Science 251:761-766.

Williams T, Admon A, Luscher B, Tjian R (1988) Cloning and expression of AP-2, a cell-type-specific transcription factor that activates inducible enhancer elements. Genes Dev 2:1557-1569

Williams T, Tjian R (1991) Analysis of the DNA-binding and activation properties of the human transcription factor AP-2. Genes Dev 5:670-682.

Wilson D, Sheng G, Lecuit T, Dostatni N, Desplan C (1993) Cooperative dimerization of paired class homen domains on DNA. Genes Dev 7:2120-2134.

Wong SC, Moffat MA, O'Malley KL (1994) Sequences distal to the AP1/E box motif are involved in the cell type-specific expression of the rat tyrosine hydroxylase gene. J Neurochem 62:1691-1697.

Yoon SO, Chikaraishi DM (1994) Isolation of two E-box binding factors that interact with the rat tyrosine hydroxylase enhancer. J Biol Chem 269:18453-18462.

Yoon SO, Chikaraishi DM (1992) Tissue-specific transcription of the rat tyrosine hydroyxlase gene requires synergy between an AP-1 motif and an overlapping $E$ box-containing dyad. Neuron 9:55-67.

Zhae G-Q, Zhou X, Eberspaecher H, Solursh M, de Crombrugghe B (1993) Cartilage homeoprotein 1, a homeoprotein selectively expressed in chondrocytes. Proc Natl Acad Sci USA 90:8633-8637. 